\title{
Effect of cardiac surgery on maternal and perinatal outcome in rheumatic heart disease with pregnancy: a comparative study
}

\author{
Vikas Yadav*, J. B. Sharma, Garima Kachhawa, \\ Alka Kriplani, Reeta Mahey, Venus Dalal, Isha Kriplani
}

Department of Obstetrics and Gynecology, AIIMS, Delhi, India

Received: 11 January 2018

Accepted: 10 February 2018

\author{
*Correspondence: \\ Dr. Vikas Yadav, \\ E-mail: vikiyadav1789@gmail.com
}

Copyright: (C) the author(s), publisher and licensee Medip Academy. This is an open-access article distributed under the terms of the Creative Commons Attribution Non-Commercial License, which permits unrestricted non-commercial use, distribution, and reproduction in any medium, provided the original work is properly cited.

\begin{abstract}
Background: Rheumatic heart disease remains the commonest heart disease in India with mitral stenosis being the most common lesion and is associated with significant maternal and perinatal mortality and morbidity. The objective of this study was to compare maternal and perinatal outcome in women with rheumatic heart valvular disease who had no surgery or had percutaneous balloon mitral valvuloplasty (PBMV) or had valvular replacement surgery.

Methods: It was a retrospective study in 113 women with rheumatic heart disease with various valvular lesion admitted in the hospital in previous 10 years. There were $58(51.35 \%)$ patients without cardiac surgery (Group 1), 24 $(21.23 \%)$ with PTMC (Group 2) and 31 (27.43\%) with valve replacement surgery (Group 3). Maternal and perinatal outcome were compared in three groups.

Results: The baseline characteristics were similar in the three group. In cardiac complications New York Heart Association (NYHA) deterioration was significantly higher (24.1\%) in non-operated group (Group 1) as compared to Group $2(12.3 \%)$ and Group $3(16.1 \%)$. There was no difference in Group 2 and Group 3. Need of cardiac medication (digoxin) was also highest (67.2\%) in Group 1 as compared to Group $2(24.6 \%)(\mathrm{p}=0.002)$ and Group $3(38.7 \%)(\mathrm{p}=$ 0.001 ) but no difference in Group 2 and Group 3. Anticoagulant were given to significantly higher number $(54.8 \%$ of cases in Group 3 (valve replacement) as compared to Group 1 (3.4\%) and Group 2 (12.5\%). There was no significant difference in obstetric events and mode of delivery in the three groups. Similarly, there was no difference in fetal outcome in the three groups as regard to mean birth weight, APGAR score, fetal growth restriction, fetal or neonatal death or congenital anomalies in the three groups.

Conclusions: Cardiac surgery before or during pregnancy did not significantly improve maternal or perinatal outcome. Only cardiac events and need of medication was reduced with surgery. Hence surgery should be performed judiciously in selected cases.
\end{abstract}

Keywords: PBMV, Rheumatic heart disease, Valvular replacement surgery

\section{INTRODUCTION}

Rheumatic heart disease remains the commonest heart disease in India with mitral stenosis being the most common lesion and is associated with significant maternal and perinatal mortality and morbidity. ${ }^{1,2}$ Maternal mortality usually occurs in cases with New
York Heart Association (NYHA) 3 and 4 and in presence of atrial fibrillation. ${ }^{3,4}$ The hemodynamic stress of pregnancy ,thromboembolism and atrial fibrillation can precipitate pulmonary edema and cardiogenic shock in patients with valvular heart disease especially mitral stenosis. ${ }^{2}$ In normal pregnancy, patient tolerate increased cardiac outcome as well as there is no pressure gradient across the normal valves. ${ }^{1}$ However in presence of a 
stenotic valve like mitral stenosis, a gradient develops between left atrium and ventricle as per the severity of mitral stenosis. ${ }^{1,2}$ This results in increase in left atrial pressure, which in turn causes pulmonary edema, increase in pulmonary artery pressure, increased right ventricular pressure and ultimately right ventricular failure. ${ }^{5}$ It can also cause left heart failure and pulmonary edema. ${ }^{5-7}$ Mitral stenosis is identified according to the valve area; mild stenosis (valve area between $<4 \mathrm{~cm}^{2}$ but $>1.5 \mathrm{~cm}^{2}$ ), moderate stenosis (valve area $1.5-1 \mathrm{~cm}^{2}$ ) severe $<1 \mathrm{~cm}^{2}{ }^{6,8}$ Severe mitral stenosis during pregnancy can cause cardiac failure necessitating prolonged period of bed rest, hospitalization and may even require surgery during pregnancy for intractable heart failure. ${ }^{9,10}$ In olden days closed or open mitral valve commissurotomy was performed during pregnancy with significant fetal mortality due to anaesthesia, thoracotomy and extracorporeal circulation during pregnancy. ${ }^{11,12}$ With the introduction of percutaneous balloon mitral valvuloplasty (PBMV) fetal loss rate has reduced significantly and was performed in the catherization laboratory under local anaesthesia by a trans septal, anterograde technique as described by Inoue et al in which right jugular vein for introduction of a Swan-Ganz catheter, left femoral artery for the introduction of a pigtail catheter and the right femoral vein for the dilation catheter were used. ${ }^{13}$

A recent study by Kumar $\mathrm{V}$ et al from Kerala, India found percutaneous mitral valvotomy during pregnancy a safe procedure providing excellent symptomatic relief and hemodynamic improvement. ${ }^{14}$ They considered it a treatment of choice for management of pregnant women with severe mitral stenosis. Mishra et al and Singh et al from India also found percutaneous trans septal mitral commissurotomy in pregnant women with critical mitral stenosis as an effective and safe procedure. ${ }^{15,16}$ The present retrospective study was conducted to compare the maternal and perinatal outcome in women of rheumatic heart disease with valvular lesion to evaluate the efficacy of valvular surgery before or during pregnancy as compared to no surgery.

\section{METHODS}

It was a retrospective study on 113 pregnant women with rheumatic heart disease with valvular defects who delivered in our institute which is a tertiary referral centre with facilities of cardiac centre and cardiac surgery in previous 10 years from April 2007 to December 2016. Data was retrieved from hospital data base after approval from concerned authority for which ethical approval was not required. Pregnant patients with congenital heart disease, cardiomyopathies and other cardiac disease were excluded. The women were divided into 3 Groups, Group 1 had $58(51.32 \%)$ women who had no surgery; Group 2 had $24(21.35 \%)$ who had percutaneous balloon mitral valvuloplasty (PBMV) during or before pregnancy and Group 3 had 31 patients $(27.43 \%)$ who had valve replacement or valve repair surgery before pregnancy. All patients were regularly seen in obstetric antenatal clinic and in cardiac clinic. Investigations were performed as per protocol. Characteristics of the patients were noted including their age (range and mean), obstetric history, time since diagnosis from pregnancy, associated medical problem, New York Heart Association classification of all patients was noted at beginning and in all subsequent visits. All patients were followed up for any obstetric, cardiac or medical complication and need of medication. The women were educated to report in the event of any complication or deterioration in their cardiac status or symptoms of cardiac failure. Obstetric events and any obstetric complications were noted in all women on every visit. Mode of delivery, any instrumental delivery or caesarean section were noted in all the women. Fetal outcome was also noted in all the patients as regard to mean birth weight, any growth restriction, APGAR score, any still birth, congenital anomalies and neonatal complications.

\section{Statistical analysis}

Data analysis was carried out using statistical software STATA version 12.0. Continuous variables were tested for normality assumptions using appropriate statistical tests. For the variables that were approximately to normal distribution descriptive statistics such as mean, standard deviation and the range values were calculated. For nonnormal data median values were compared. Comparison of two Group means were tested using student $t$ independent test. Comparison of more than two Group means were tested using one-way ANOVA test. Categorical variables were expressed in terms of frequency and percent values. Frequency data by categories was compared using chi square test/Fischer exact test as appropriate. Two-sided probabilities $\mathrm{P}<0.05$ was considered for statistical significance.

\section{RESULTS}

A total of 113 patients with rheumatic heart disease with various cardiac lesions who delivered in our hospital in last 10 years were included in this retrospective study. The various types of cardiac lesions are shown in Table 1 .

Table 1: Type of cardiac lesion in the patients.

\begin{tabular}{|lll|}
\hline Cardiac condition & No. & Percentage (\%) \\
\hline $\begin{array}{l}\text { Rheumatic heart disease } \\
\text { Type of lesion }\end{array}$ & 113 & 100 \\
\hline MS & 70 & 61.94 \\
\hline MS+MR & 20 & 17.69 \\
\hline MR & 18 & 15.92 \\
\hline AS & 2 & 1.76 \\
\hline AR & 12 & 10.61 \\
\hline PAH & 7 & 6.19 \\
\hline Multivalvular & 24 & 21.23 \\
\hline
\end{tabular}

MS: Mitral Stenosis; MR: Mitral Regurgitation; AS: Aortic Stenosis; AR: Aortic Regurgitation; PAH: Pulmonary Artery Hypertension 
Mitral stenosis was the commonest lesion seen alone in $70(61.94 \%)$ cases and with mitral regurgitation seen in $20(17.69 \%)$ cases. Mitral regurgitation alone was seen in $18(15.92 \%)$ cases. Other lesions are shown in Table 1. The baseline characteristics of the patients in three Groups are shown in Table 2. There were $58(51.31 \%)$ cases in Group 1 (non-operated cases), 24 (21.23\%) cases in Group 2 (PBMV) and $31(27.43 \%)$ cases in Group 3 (post valve replacement). There was no significant difference in mean age, obstetric history, time since diagnosis from pregnancy, New York Heart Association (NYHA) classification and associated medical problems in the three Groups. Table 3 shows cardiac complications and need of cardiac medication in the 3 Groups. NYHA deterioration was significantly higher $(24.1 \%)$ in Group 1 (non-operated) as compared to Group 2 (12.3\%) (post PBMV) $(\mathrm{P}=0.008)$ and also as compared to Group 3 (post valve replacement) $(16.1 \%)(\mathrm{p}=0.004)$. However, there was no significant difference in Group 2 and Group 3 in NYHA deterioration $(\mathrm{p}=0.0424)$. There was no significant difference in other cardiac complications in the three Groups. There was significant increased need of cardiac medication digoxin in Group 1 (67.2\%) as compared to Group $2(24.6 \%)(\mathrm{p}=0.002)$ and Group 3 $(38.7 \%)(\mathrm{p}=0.002)$ but no difference in Group 2 and Group $3(\mathrm{p}>0.05)$.

Need of anticoagulation therapy was significantly higher in Group 3 (post valve replacement) (54.8\%) as compared to Group $1(3.4 \%)$ ( $\mathrm{p}<0.05)$ and Group 2 $(12.5 \%)$ ( $\mathrm{p}<0.05)$ but no difference in Group 1 and Group $2(p=0.53)$. It was due to relative risk of thrombosis in mechanical valve replacement Group.

Table 2: Baseline characteristics in the 3 groups.

\begin{tabular}{|c|c|c|c|c|}
\hline Outcome & $\begin{array}{l}\text { Group } 1 \text { Non- } \\
\text { operated No. }(\%) \\
\mathbf{N}=\mathbf{5 8}(\mathbf{5 1 . 3 2})\end{array}$ & $\begin{array}{l}\text { Group } 2 \text { Post } \\
\text { PBMV No. }(\%) \\
\text { N }=24(21.23)\end{array}$ & $\begin{array}{l}\text { Group } 3 \text { Post valve } \\
\text { replacement/repair } \\
\text { No. }(\%) \mathbf{N}=31(27.43)\end{array}$ & $\begin{array}{l}P \text { value and } \\
\text { significance }\end{array}$ \\
\hline Mean age & $26.12 \pm 3.93$ & $25.54 \pm 3.68$ & $26.35 \pm 3.82$ & \multirow{4}{*}{$\mathrm{P}=0.730 \mathrm{NS}$} \\
\hline$<18$ & 0 & 0 & 0 & \\
\hline $18-35$ & $55(94.8)$ & $24(100)$ & $30(96.7)$ & \\
\hline$>35$ & $3(5.1)$ & 0 & $1(3.3)$ & \\
\hline \multicolumn{4}{|l|}{ Obstetric history } & \multirow{3}{*}{$\mathrm{P}=0.695 \mathrm{NS}$} \\
\hline Primigravida & $22(37.9)$ & $8(33.3)$ & $9(29)$ & \\
\hline Multigravida & $36(62)$ & $16(66.6)$ & $22(70.9)$ & \\
\hline \multicolumn{4}{|c|}{ Time since diagnosis from pregnancy } & \multirow{5}{*}{$\mathrm{P}=0.05 \mathrm{NS}$} \\
\hline$<10$ years & $33(56.8)$ & $22(91.6)$ & $18(58)$ & \\
\hline $10-20$ years & $5(8.6)$ & $2(8.3)$ & $13(41.9)$ & \\
\hline$>20$ years & $3(5.1)$ & 0 & 0 & \\
\hline During pregnancy & $18(31)$ & 0 & 0 & \\
\hline \multicolumn{4}{|l|}{ NYHA class } & \multirow{5}{*}{$\mathrm{P}=0.145 \mathrm{NS}$} \\
\hline NYHA 1 & $41(70.6)$ & $15(62.5)$ & $26(83.8)$ & \\
\hline NYHA 2 & $12(20.6)$ & $8(33.3)$ & $4(12.9)$ & \\
\hline NYHA 3 & $5(8.6)$ & 0 & $1(3.2)$ & \\
\hline NYHA 4 & 0 & $1(4.1)$ & 0 & \\
\hline \multicolumn{4}{|c|}{ Associated medical problems } & \multirow{10}{*}{$\mathrm{P}>0.05 \mathrm{NS}$} \\
\hline Chronic HTN & $1(1.7)$ & 0 & 0 & \\
\hline Hypothyroid & $4(6.8)$ & 0 & $1(3.2)$ & \\
\hline LRTI & $2(3.4)$ & $1(4.1)$ & 0 & \\
\hline AKI & $1(1.7)$ & 0 & 0 & \\
\hline CKD & $1(1.7)$ & 0 & 0 & \\
\hline Seizure disorder & 0 & 0 & $1(3.2)$ & \\
\hline KOCH'S & 0 & $1(4.1)$ & 0 & \\
\hline CVA & $2(3.4)$ & 0 & 0 & \\
\hline Hepatitis/HIV & $1(1.7)$ & $2(8.2)$ & $1(3.2)$ & \\
\hline
\end{tabular}

The obstetric events in the three Groups are shown in Table 4. There was no significant difference in various obstetric events in the three Groups. Mode of delivery is also shown in Table 4. Incidence of vaginal delivery, instrumental delivery and cesarean section rate was $62.06 \%, 66.6 \%$ and $61.2 \% ; 24.1 \%, 12.5 \%$ and $29 \%$; 
$37.9 \%, 33.3 \%$ and $38.7 \%$ respectively in the three Groups and was not significantly different $(\mathrm{p}=0.934)$.

The fetal outcome in the three Groups is shown in Table 5. The mean birth weight was $2481.63 \pm 471.67 \mathrm{gm}$ in Group 1, 2399.75 \pm 601.8 in Group 2 and 2291.06 \pm 700.16 $\mathrm{gm}$ in Group 3 and was not significantly different
( $\mathrm{p}=0.34)$ APGAR score of $<8$ was seen in $10.3 \%$ cases in Group 1, 16.4\% cases in Group 2 and in $19.3 \%$ cases in Group 3 and was not significantly different $(\mathrm{p}=0.468)$. There was no significant difference in other complications like fetal growth restriction, hyperbilirubinemia, necrotizing enterocolitis, still birth, congenital anomalies in the three Groups.

Table 3: Cardiac complications and need of cardiac medications in the 3 groups.

\begin{tabular}{|c|c|c|c|c|}
\hline Outcome & $\begin{array}{l}\text { Group } 1 \\
\text { Non-operated } \\
\text { No. }(\%) \\
\mathbf{N}=\mathbf{5 8}(\mathbf{5 1 . 3 2})\end{array}$ & $\begin{array}{l}\text { Group } 2 \\
\text { Post PBMV } \\
\text { No. }(\%) \\
\text { N }=24(21.23)\end{array}$ & $\begin{array}{l}\text { Group } 3 \\
\text { post valve replacement/ } \\
\text { repair No. (\%) } \\
\mathbf{N}=\mathbf{3 1}(\mathbf{2 7 . 4 3 )}\end{array}$ & $\begin{array}{l}P \text { value and } \\
\text { significance }\end{array}$ \\
\hline \multicolumn{5}{|l|}{ Cardiac complications } \\
\hline Uneventful & $44(75.9)$ & $11(45.83)$ & $24(77.4)$ & $\begin{array}{l}\mathrm{P}=0.015 \# ; \\
1 \text { vs } 2 \mathrm{p}<0.05 \mathrm{Sig} \\
1 \text { vs } 3 \mathrm{p}=0.016 \mathrm{Sig} \\
2 \text { vs } 3 \mathrm{p}>0.05 \mathrm{NS}\end{array}$ \\
\hline Stuck valve & 0 & $2(8.33)$ & 0 & $\mathrm{p}>0.05 \mathrm{NS}$ \\
\hline $\mathrm{CCF}$ & $1(1.7)$ & 0 & 0 & $\mathrm{P}>0.05 \mathrm{NS}$ \\
\hline Arrythmia & 0 & $1(4.1)$ & 0 & $\mathrm{P}>0.05 \mathrm{NS}$ \\
\hline Restenosis & 0 & $1(4.1)$ & 0 & $\mathrm{P}>0.05 \mathrm{NS}$ \\
\hline NYHA deterioration & $14(24.1)$ & $13(12.3)$ & $5(16.1)$ & $\begin{array}{l}P=0.007 \# ; 1 \text { vs } 2 \\
p=0.008 \mathrm{Sig} \\
1 \text { vs } 3 p=0.004 \mathrm{Sig} \\
2 \text { vs } 3 p=0.429 \\
\text { NS }\end{array}$ \\
\hline $\mathrm{AF}$ & 0 & $1(4.1)$ & $2(6.4)$ & $\mathrm{P}>0.05 \mathrm{NS}$ \\
\hline \multicolumn{5}{|c|}{ Use of cardiac medication } \\
\hline Digoxin & $39(67.2)$ & $6(24.6)$ & $12(38.7)$ & $\begin{array}{l}\mathrm{P}=0.001 \# ; 1 \text { vs } 2 \\
\mathrm{p}=0.002 \mathrm{Sig} \\
1 \text { vs } 3 \mathrm{p}<0.001 \mathrm{Sig} \\
2 \text { vs } 3 \mathrm{p}>0.05 \mathrm{NS}\end{array}$ \\
\hline Diuretic & $17(29.3)$ & $16(66.6)$ & $21(67.6)$ & $\begin{array}{l}1 \text { vs } 2 p>0.05 \mathrm{NS} \\
2 \text { vs } 3 p>0.05 \mathrm{NS} \\
1 \text { vs } 3 p>0.05 \mathrm{NS}\end{array}$ \\
\hline Beta blockers & $18(31)$ & $7(29.16)$ & $6(19.3)$ & $\mathrm{P}>0.05 \mathrm{~ns}$ \\
\hline Anticoagulants & $2(3.4)$ & $3(12.5)$ & $17(54.8)$ & $\begin{array}{l}\mathrm{P}=0.001 \# ; 3 \text { vs } 1 \mathrm{p} \\
<0.05 \mathrm{Sig} \\
3 \text { vs } 2 \mathrm{p}<0.05 \mathrm{Sig} \\
1 \text { vs } 2 \mathrm{p}>0.05 \mathrm{NS}\end{array}$ \\
\hline Anti-hypertensive & $9(15.5)$ & 0 & $1(3.2)$ & $\mathrm{P}>0.05 \mathrm{NS}$ \\
\hline
\end{tabular}

CCF: Congestive cardiac failure; NYHA: New York Heart Association; AF: Atrial Fibrillation; \#: Comparison between three groups was done

\section{DISCUSSION}

Rheumatic heart disease with mitral stenosis is the commonest cardiac disease during pregnancy especially in developing countries like India. ${ }^{12,14}$ It can cause up to $1 \%$ maternal mortality if left untreated depending on the functional class of the patient. ${ }^{14}$ Significant hemodynamic changes and rise in cardiac output adversely affects pregnancy causing heart failure during pregnancy, labor and in early puerperium. ${ }^{12.14}$ Medical management is tried first but may not alone provide adequate symptomatic relief or prevent an adverse outcome. In cases with NYHA class 3-4, balloon mitral valvotomy can be performed especially in second trimester with a success rate of $94-98 \% .^{14.15}$

A recent study from Pakistan by Gulzare A et al observed mitral balloon valvuloplasty as a safe and effective procedure during pregnancy with no short or long term adverse effects on the mothers and children. ${ }^{17}$ 
The results of the present study demonstrate that if the cardiac condition is stable than surgery does not improve outcome. Infact in the present study, there was no significant difference in maternal outcome (obstetric and medical) in women of rheumatic heart disease with valvular lesion with no surgery as compared to mitral valvotomy or valvular surgery. There was however significant increased rate of NYHA class deterioration in unoperated patients $(29.5 \%)$ as compared to mitral valvotomy $(12.3 \%)$ and mitral valve replacement/repair surgery (16.1\%). Similarly need of digoxin was significantly higher $(67.2 \%)$ in non-operated cases as compared to mitral valvotomy $(24.6 \%)(\mathrm{p}=0.002)$ and valve replacement or repair surgery $(38.7 \%)(\mathrm{p}<0.001)$. Anticoagulants were obviously given more often in valve replacement cases $(54.8 \%)$ as compared to non-operated case $(3.4 \%) \quad(\mathrm{p}<0.05)$ and mitral valvotomy $(12.5 \%)$ $(\mathrm{p}<0.05)$.

Table 4: Obstetrics events in the three groups.

\begin{tabular}{|c|c|c|c|c|}
\hline Outcome & $\begin{array}{l}\text { Group } 1 \\
\text { Non-operated } \\
\text { No. }(\%) \\
\mathbf{N}=\mathbf{5 8}(\mathbf{5 1 . 3 2})\end{array}$ & $\begin{array}{l}\text { Group } 2 \\
\text { Post PBMV } \\
\text { No. }(\%) \\
\text { N }=24(21.23)\end{array}$ & $\begin{array}{l}\text { Group } 3 \\
\text { Post valve } \\
\text { replacement/repair } \\
\text { No. }(\%) \mathbf{N}=\mathbf{3 1}(\mathbf{2 7 . 4 3 )}\end{array}$ & $\begin{array}{l}\mathbf{P} \text { value and } \\
\text { Significance }\end{array}$ \\
\hline \multicolumn{5}{|l|}{ Obstetric events } \\
\hline Anemia & $9(15.5)$ & $1(4.1)$ & $3(9.6)$ & $\begin{array}{l}1 \text { vs } 2 p>0.0 .05 \mathrm{NS} \\
2 \text { vs } 3 p>0.05 \mathrm{NS} \\
1 \text { vs } 3 p>0.05 \mathrm{NS}\end{array}$ \\
\hline Pre-eclampsia & $4(6.8)$ & 0 & 0 & $\begin{array}{l}1 \text { vs } 2 p>0.05 N S \\
2 \text { vs } 3 p>0.05 N S \\
1 \text { vs } 3 p>0.05 N S\end{array}$ \\
\hline Oligoamnios & $2(3.4)$ & 0 & $3(9.6)$ & $\mathrm{P}>0.05 \mathrm{NS}$ \\
\hline Gdm & $5(8.6)$ & $2(8.2)$ & $1(3.2)$ & $\begin{array}{l}1 \text { vs } 2 p>0.05 \mathrm{NS} \\
2 \text { vs } 3 p>0.05 \mathrm{NS} \\
1 \text { vs } 3 p>0.05 \mathrm{NS}\end{array}$ \\
\hline Aph & 0 & 0 & $2(6.4)$ & $\mathrm{P}>0.05 \mathrm{NS}$ \\
\hline Prom & $1(1.7)$ & $2(8.2)$ & $2(6.4)$ & $\mathrm{P}>0.05 \mathrm{NS}$ \\
\hline Icp & $3(5.1)$ & $2(8.2)$ & $2(6.4)$ & $\begin{array}{l}1 \text { vs } 2 p>0.05 \mathrm{NS} \\
2 \text { vs } 3 p>0.05 \mathrm{NS} \\
1 \text { vs } 3 p>0.05 \mathrm{NS}\end{array}$ \\
\hline Previous lscs & $3(5.1)$ & $6(25)$ & $2(6.4)$ & $\mathrm{P}=0.235 \mathrm{NS}$ \\
\hline $\begin{array}{l}\text { Post-partum } \\
\text { complication }\end{array}$ & 0 & $1(4.1)$ & $1(3.2)$ & $\mathrm{P}=0.934 \mathrm{NS}$ \\
\hline \multicolumn{5}{|l|}{ Mode of delivery } \\
\hline Vaginal & $36(62.06)$ & $16(66.6)$ & $19(61.2)$ & $1 \mathrm{vs} 2 \mathrm{p}>0.05 \mathrm{NS}$ \\
\hline Spontaneous & $32(55.1)$ & $13(54.1)$ & $18(58)$ & 2 vs $3 p>0.05 \mathrm{NS}$ \\
\hline Induced & $4(6.8)$ & $3(12.5)$ & $1(3.2)$ & 1 vs $3 p>0.05 \mathrm{NS}$ \\
\hline Use of forceps/ventouse & $14(24.1)$ & $3(12.5)$ & $9(29)$ & \\
\hline LSCS & $22(37.9)$ & $8(33.3)$ & $12(38.7)$ & \multirow{3}{*}{$\mathrm{P}=0.934 \mathrm{NS}$} \\
\hline Elective & $3(5.1)$ & $3(12.5)$ & $2(6.4)$ & \\
\hline Emergency & $19(32.7)$ & $5(20.8)$ & $10(32.2)$ & \\
\hline
\end{tabular}

GDM: Gestational diabetes mellitus; APH: Antepartum hemorrhage; ICP: Intrahepatic cholestasis of pregnancy; PROM: Premature rupture of membrane

Various obstetric events like anemia, pre-eclampsia, oligoamnios, gestational diabetes, antepartum hemorrhage, intrahepatic cholestasis was similar in three groups.

Similarly, the perinatal outcome was also similar in the three groups with no difference in mean birth weight, still birth rate, congenital malformation, low APGAR score and other neonatal complications.

The incidence of vaginal delivery was also similar in the three Groups $(62.06 \%, 66.6 \%$ and $61.2 \%)$. Similarly, incidence of instrumental delivery $(24.1 \%, 12.5 \%$ and $29 \%$ ) was also similar in the three groups. Caesarean section rate was also not significantly different in the 
three groups being $37.9 \%$ in non-operated Group,33.3\% in mitral valvotomy group and $38.7 \%$ in valve replacement or repair group.
The results of present study donor show any improvement in maternal or perinatal outcome with mitral valvotomy or valve replacement before surgery.

Table 5: Fetal outcome in the three groups.

\begin{tabular}{|c|c|c|c|c|}
\hline Outcome & $\begin{array}{l}\text { Group } 1 \\
\text { Non-operated } \\
\text { No. }(\%) \\
\mathbf{N}=\mathbf{5 8}(\mathbf{5 1 . 3 2})\end{array}$ & $\begin{array}{l}\text { Group } 2 \\
\text { Post PBMV } \\
\text { No. }(\%) \\
\text { N }=\mathbf{2 4}(\mathbf{2 1 . 2 3 )}\end{array}$ & $\begin{array}{l}\text { Group } 3 \\
\text { Post valve replacement/repair } \\
\text { No. }(\%) \\
\mathbf{N}=\mathbf{3 1}(\mathbf{2 7 . 4 3 )}\end{array}$ & $\begin{array}{l}\text { P value and } \\
\text { Significance }\end{array}$ \\
\hline \multicolumn{5}{|l|}{ Fetal outcome } \\
\hline Mean birth weight & $2481.63 \pm 471.47$ & $2399.75 \pm 601.8$ & $2291.06 \pm 700.16$ & $\mathrm{P}=0.324 \mathrm{NS}$ \\
\hline Fgr & $3(5.1)$ & $4(16.4)$ & $1(3.2)$ & $\begin{array}{l}1 \text { vs } 2 p=0.157 \mathrm{NS} \\
2 \text { vs } 3 p=0.156 \mathrm{NS} \\
1 \text { vs } 3 p=0.94 \mathrm{NS}\end{array}$ \\
\hline Lfd & 0 & 0 & 0 & $\mathrm{P}>0.05 \mathrm{NS}$ \\
\hline Hyperbilirubinemia & $1(1.7)$ & 0 & 0 & $\mathrm{P}>0.05 \mathrm{NS}$ \\
\hline $\mathrm{Nec}$ & $1(1.7)$ & 0 & 0 & $\mathrm{P}>0.05 \mathrm{NS}$ \\
\hline Rop & $1(1.7)$ & 0 & 0 & $\mathrm{P}>0.05 \mathrm{NS}$ \\
\hline Bpd & $1(1.7)$ & 0 & 0 & $\mathrm{P}>0.05 \mathrm{NS}$ \\
\hline Apgar $<8$ & $6(10.2)$ & $4(16.4)$ & $6(19.3)$ & $\begin{array}{l}1 \text { vs } 2 p=0.468 \mathrm{NS} \\
2 \text { vs } 3 p>0.05 \mathrm{NS} \\
1 \text { vs } 3 p>0.05 \mathrm{NS}\end{array}$ \\
\hline Still birth & 0 & $2(8.2)$ & $2(6.4)$ & $\mathrm{P}=0.071 \mathrm{NS}$ \\
\hline Congenital anomaly & $3(5.1)$ & $2(8.2)$ & $1(3.2)$ & $\mathrm{P}=0.739 \mathrm{NS}$ \\
\hline
\end{tabular}

FGR: Fetal growth restriction; LFD: Large for date; NEC: Necrotizing enterocolitis; ROP: Retinopathy of prematurity; BPD: Bronchopulmonary dysplasia

However, it was a retrospective study and surgery was performed as per need of the patient. There was likelihood of surgery in more severe cases with critical valvular construction before pregnancy or during pregnancy. However, the comparison was not homogenous. The maternal and perinatal outcome might have been worse if surgery was not performed in these severe cases.

The drawback of the study is that it is a retrospective analysis and that surgery was performed as per the need of the patient with more severe heart disease.

To conclude cardiac disease in pregnancy is a high-risk pregnancy with high maternal and perinatal mortality and morbidity. There is need to have a good collaboration between obstetrician, cardiologist, anesthetist, paediatrician for better outcome. Such patients should be managed in tertiary referral centre with facility for cardiology and surgery for optimum outcome. Ideally all patients of severe cardiac disease should be optimally managed before pregnancy either by mitral valvotomy or by valve replacement for optimum outcome. ${ }^{18-20}$

\section{CONCLUSION}

Cardiac surgery before or during pregnancy did not significantly improve maternal or perinatal outcome.
Only cardiac events and need of medication was reduced with surgery. Hence surgery should be performed judiciously in selected cases.

\section{ACKNOWLEDGMENTS}

We are thankful to all faculty and residents of Department of Obstetrics and Gynecology and Department of Cardiology.

\section{Funding: No funding sources}

Conflict of interest: None declared

Ethical approval: The study was approved by the Institutional Ethics Committee

\section{REFERENCES}

1. Malhotra M, Sharma JB, Arora P. Mitral valve surgery and maternal and fetal outcome in valvular heart disease. Int J Gynecol Obstet. 2003;81:151-6.

2. Gupta A, Yash Y. Balloon mitral valvotomy in pregnancy: maternal and fetal outcomes. J Am Col Surg. 1998;187:409-15.

3. Warnes CA. Pregnancy and heart disease.: Braunwald's Heart Disease: a textbook of cardiovascular medicine. $9^{\text {th }}$ ed. Elsevier; 2011:17701782. 
4. McAnulty JH. Heart disease and pregnancy. In: Hurst the Heart. 13 ${ }^{\text {th }}$ ed. 2011:2146-2158.

5. Desai DK, Lawo AM, Naidoo DP. Mitral stenosis in pregnancy: a five-year experience at King Edward. BJOG. 2000;107:953-7.

6. Deans CL, Uebing A, Stear P. Cardiac disease in pregnancy. In Studd J, Tan SL, Chervenak FA. cedss Progress in Obstetrics and Gynaecology Elsevier, Edinburgh; 2006;17:164-182

7. Malhotra M, Sharma J B, Tripathi R, Arora P. Mitral valve surgery and maternal and fetal outcome in valvular heart disease. Int $\mathbf{J}$ Gynecol Obstet. 2004;84:11-16

8. Sawhney H, Aggarwal N, Suri V. Maternal and perinatal outcome in rheumatic heart disease. Int $\mathrm{J}$ Gynecol Obstet. 2003;80:9.

9. Jose AM, de Souza, Eulogio E. Percutaneous balloon mitral valvuloplasty in comparison with pen mitral valve commissurotomy for mitral stenosis during pregnancy. J Am Col Card. 2001;37:900.

10. A' vila WS, Grinberg M, De'court LV, Bellotti G, Pileggi F. Evolution of mitral stenosis carriers in the pregnancy-puerperal cycle. Arq Bras Cardiol. 1992;58:359-64.

11. Nercolini DC, Bueno RRL, Guerios E, Tarastchuck JC, Kubrusly LF. Percutaneous mitral balloon valvuloplasty in pregnant women with mitral stenosis. Cathet Cardiovasc Intervent. 2002;57:31822.

12. Goon MS, Raman S, Sinnathuray TA. Closed mitral valvotomy in pregnancy: a Malayasian experience. Aust N Z J Obstet Gynaecol. 1987;27:173-7.

13. Inoue $\mathrm{K}$, Owaki $\mathrm{T}$, Nakamura $\mathrm{T}$, Kitamura $\mathrm{F}$, Miyamoto N. Clinical application of transvenous mitral commissurotomy by a new balloon catheter. J Thorac Cardiovasc Surg. 1984;87:394-402.
14. Vinayakumar D, Vinod GV, Madhavan S, Krishnan MN. Maternal and fetal outcomes in pregnant women undergoing balloon mitral valvotomy for rheumatic mitral stenosis. Indian Heart J. 2016;68(6):780-2.

15. Mishra S, Narang R, Sharma M. Percutaneous transseptal mitral commissurotomy in pregnant women with critical mitral stenosis. Indian Heart J. 2001; 53:192-6.

16. Singh $\mathrm{Y}$, Manjunath $\mathrm{C}$, Nanjappa. Immediate and intermediate-term out-comes of percutaneous transvenous mitral commissurotomy during pregnancy: our experience with accura balloon at a high-volume center. Indian Heart J. 2013;65:S33-93.

17. Gulzare A, Kurdi W, Niaz FA. Mitral balloon valvuloplasty during pregnancy: the long term up to 17 years obstetric outcome and childhood development. Pak J Med Sci. 2014;30:86-90.

18. Wasim T, Amer W, Majrroh A. Fetomaternal outcome of pregnancy with cardiac disease. J Pak Med Assoc. 2008;58:175-8.

19. Mihaljevic T, Paul S, Leacche M, Rawn JD, Cohn LH, Byrne JG. Valve replacement in women of childbearing age: influences on mother, fetus and neonate. J Heart Valve Dis. 2005;14(2):151-7.

20. Bhatla N, Lal S, Behera G, Kriplani A, Mittal S, et al. Cardiac disease in pregnancy. Int $\mathbf{J}$ Gynecol Obstet. 2003;82:153-9.

Cite this article as: Yadav V, Sharma JB, Kachhawa G, Kriplani A, Mahey R, Dalal V, et al. Effect of cardiac surgery on maternal and perinatal outcome in rheumatic heart disease with pregnancy: a comparative study Int J Reprod Contracept Obstet Gynecol 2018;7:1123-9. 